\title{
Biliary access during endoscopic retrograde cholangiopancreatography
}

\author{
David L Carr-Locke MD FRCP
}

DL Carr-Locke. Biliary access during endoscopic retrograde cholangiopancreatography. Can J Gastroenterol 2004;18(4):251-254.

Several techniques have been developed to facilitate cannulation of the papilla during endoscopic retrograde cholangiopancreatography (ERCP). The position of the endoscope should generally provide a 'straight' route to the papilla, and the efforts should be directed at shortening the intraduodenal portion of the bile duct. If a guidewire is used, one should be chosen that possesses suitable tip and shaft characteristics, including flexibility, strength, low friction and trackability, but no one device is likely to be suitable for all purposes. The development of guidewires composed of nitinol has revolutionized endoscopic practice. Access papillotomy ('pre-cut') can be employed as an alternative to (or in addition to) insertion of a guidewire when cannulation of the major papilla has been unsuccessful. The same techniques may be used to allow deep cannulation of the bile or pancreatic duct after ductography, when fluoroscopy can also be used. The 'needle-knife', which must be used carefully because it cuts with even slight tissue contact, is moved in the expected direction of the intramural bile (or pancreatic) duct to gain direct access into the duct. Access papillotomy is a valuable procedure in difficult cases, but is associated with greater risks than standard ERCP techniques (except perhaps for a reduced likelihood of pancreatitis), and is best employed by personnel who have extensive experience with therapeutic endoscopy. Technical details for a variety of clinical situations are described. Success requires application of 'the four Ps': position, practice, patience and perseverance.

Key Words: Access papillotomy; Bile duct cannulation; ERCP; Needle-knife papillotome; Precut papillotomy; Therapeutic endoscopy

\section{Laccès biliaire pendant une cholangiopan- créatographie rétrograde endoscopique}

Plusieurs techniques ont été élaborées pour faciliter la canulation de la papille pendant la cholangiopancréatographie rétrograde endoscopique (CPRE). D'ordinaire, la position de l'endoscope devrait assurer une voie directe vers la papille, et les efforts devraient être orientés vers la diminution de la portion intraduodénale du canal cholédoque. Si un fil-guide est utilisé, il faut en choisir un dont le bout et la tige possèdent les bonnes caractéristiques, y compris la flexibilité, la force, la friction réduite et la traçabilité, mais il est peu probable qu'un seul instrument convienne à tous les objectifs. La mise au point de fils-guides de nitinol a révolutionné l'endoscopie. La papillotomie d'accès (précoupe) peut remplacer (ou compléter) l'insertion d'un fil-guide lorsque la canulation de la principale papille échoue. Les mêmes techniques peuvent être utilisées pour permettre une canulation profonde du canal cholédoque ou pancréatique après la galactographie, lorsqu'il est aussi possible de recourir à une fluoroscopie. Le bistouri aiguille, qui doit être utilisé avec vigilance parce qu'il coupe même lors d'un léger contact avec les tissus, est déplacé dans la direction prévue du canal cholédoque (ou pancréatique) intramural pour donner un accès direct au canal. La papillotomie d'accès est une intervention précieuse dans les cas difficiles, mais elle s'associe à des risques plus élevés que les techniques de CPRE standard (sauf, peut-être, pour diminuer la probabilité de pancréatite), et elle est mieux utilisée par du personnel qui possède une vaste expérience de l'endoscopie thérapeutique. Les détails techniques de diverses situations cliniques sont décrits. Le succès exige l'application des « quatre $\mathrm{P} »$ : position, pratique, patience et persévérance.
C annulation of the papilla during endoscopic retrograde cholangiopancreatography (ERCP) is often challenging to even skilled endoscopists. Many components of cannulation and access techniques are evanescent art forms that require careful application and meticulous application if they are to be mastered. Consequences of failed cannulation include increased morbidity and mortality, incomplete diagnosis and treatment, increased cost and injury to the endoscopist's ego.

Table 1 lists the requirements for consistently successful cannulation of the major papilla. The ideal ERCP suite should contain all necessary guidewires and accessories close to the procedure area. Clear labelling of the storage area and routine use of a limited number of devices can reduce search time.
Good ergonomics dictate that the television monitors for endoscopy and fluoroscopy are side-by-side and equally visible to the endoscopist and assistant. High-resolution fluoroscopy equipment is essential and should feature digital image holding and magnification. If hard copy films are being generated, processing should be rapid and nearby to allow easy reference during a procedure.

The endoscopist must understand the anatomy of the duodenum, papilla and bile duct. The fully prone position is usually best for the patient during cannulation, but some centres employ other positions routinely, and special circumstances may require supine or semi-prone positions. It is important to achieve and maintain a good endoscope position, which

Presented at the $16^{\text {th }}$ International Course on Therapeutic Endoscopy, Toronto, Ontario, October 2003

Gastroenterology Division, Brigham and Women's Hospital, Boston, Massachusetts 02115, USA

Correspondence: Dr David L Carr-Locke, Endoscopy Center, Brigham and Women's Hospital, 75 Francis Street, Boston, Massachusetts 02115 ,

USA. Telephone 617-732-7414 or 617-732-7157, fax 617-264-5171, e-mail dcarrlocke@partners.org

Received and accepted for publication March 4, 2004 


TABLE 1
Requirements for consistent success at therapeutic
endoscopic retrograde cholangiopancreatography (ERCP)
A cooperative patient who has a clear indication for ERCP
A trained team of endoscopy and radiology personnel that work well
together
A suitable duodenoscope that permits rapid and accurate visualization of
the papilla and facilitates placement of appropriate accessory instruments
A range of accessories, including the following:
Cannula with standard and modified tips (according to personal
preference)
Standard 0.035 -inch guidewires
Special wires for difficult situations
Standard 20 - or 30 -mm sphincterotomes with separate lumens for
guidewire access
An all-purpose contrast medium, such as Renograffin or Hypaque $60 \%$.
A well-equipped fluoroscopy suite that provides high-quality television
images during contrast injection and manipulation of accessories as well
as 'last image held' mode, and the rapid availability of hard copy films
Knowledge of normal anatomy and possible abnormalities and of the range
of techniques that are needed to achieve the intended goal

should provide a 'straight' route to the papilla. The direction may need to be altered in patients who have undergone gastroduodenal surgery. Duodenal motility can be reduced by the judicious use of glucagon or an anticholinergic agent. Cannulation and contrast injection must be coordinated, whether performed by one or two operators.

The endoscopist must develop skill in manipulating six two-directional vectors simultaneously, namely:

- advancement/withdrawal of the endoscope;

- right/left movements of the tip;

- up/down movements of the tip;

- right/left rotation of the control body;

- up/down control of the elevator; and

- push/pull positioning of the catheter or accessory.

If a sphincterotome is being used for cannulation, two further vectors are added - up or down movements of the tip - by applying or releasing tension on the handle.

\section{GUIDEWIRES}

The use of guidewires has become an integral part of diagnostic and therapeutic ERCP, and success often depends on the choice and of the most appropriate guidewire and its correct manipulation. Accurate placement of the guidewire requires clear instructions and communication between the operators. The optimal physical attributes of the guidewire depend on the specific application, and include tip length and flexibility, axial and lateral strength of the shaft, surface friction, torque transmission, radio-opacity and electrical conductivity.

The two main attributes of guidewires for endoscopy are access and trackability. In general, a highly flexible slippery tip, with or without angulation to allow torquing, is desirable for entry across the papilla into a duct, across a stricture, into a branch duct or into a stent or cyst. Conversely, trackability refers to the ease with which other devices (eg, catheters, stent systems, sphincterotomes, cytology sheaths, dilators, balloons, stent extractors or miniscopes) can be passed along the axis of the guidewire, and demands a stiffer shaft that can be made taut and as curvilinear as possible.

Low surface friction enables advancement of the guidewire with less axial force but may decrease the ability to maintain tension without losing position. On the other hand, increased friction helps to maintain wire tension at the expense of impeding device movement. In addition, the presence of friction between the guidewire and the device makes it necessary to apply opposing forces (for example, pushing the device while pulling the guidewire) to aid in the advancement of the device. Newton's Laws of Motion (if forces are equal and opposite, no movement will occur) still apply to low friction or 'frictionless' guidewires. Therefore, the use of one guidewire for all purposes involves a compromise, although many wires possess enough design characteristics to fulfill many of our needs.

Guidewires are composed of the inner core and outer coating (sheath) of the shaft and the tip. The original device, still called the standard wire, is a stainless steel monofilament core covered by a stainless steel coil painted with a thin layer of Teflon to reduce surface friction. The tip is made flexible by tapering the inner core, which may also be made movable. The entire wire is densely radio-opaque. These wires are the least expensive and possess considerable axial strength, but are easily kinked and have significant friction at the sheath and poor radiofrequency electrical insulation due, in part, to defects in the Teflon coating. Because there is a small risk of conducting current to the assistant, they are not suitable for sphincterotomy, and should be pulled back into the sphincterotome or removed completely before applying cautery. The risk has been reduced by the use of modern sphincterotomes that carry a separate guidewire lumen.

The introduction of memory metals, such as nitinol (Nickel Titanium Naval Ordnance Laboratory) from military research, has spawned the development of strong, flexible guidewires that do not kink and exhibit little friction. Characteristics of specific wires are listed in Table 2. Surface coatings may be confined to the tip or the entire guidewire. Wires also vary according to stiffness, because nitinol can be manufactured to many specifications. Because nitinol is poorly seen at fluoroscopy, a radiodense material, such as platinum or tungsten, is often incorporated in the tip. The tip is also tapered to enhance flexibility and may or may not have a slippery hydrophilic coating. The external surface of some guidewires has stripes or graduated markings that aid positioning during exchanges, decrease the need for continuous fluoroscopy and allow measurement of linear distance for stent length assessment. Several guidewires are marketed as sphincterotomy compatible (Table 2), but probably all intact coated wires are adequately insulated when used with sphincterotomes that contain a dedicated guidewire lumen.

The guidewire should be at least $20 \mathrm{~cm}$ more than twice the length of the accessory being exchanged. Lengths of $400 \mathrm{~cm}$, $450 \mathrm{~cm}$ or $480 \mathrm{~cm}$ are available, and the latter two are sufficient for all ERCP applications, including the rare use of an enteroscope for patients with surgically altered anatomy. As an alternative, Cialfi and Carr-Locke (unpublished) have developed methods for using a 260-cm completely hydrophilic guidewire, which avoids the need to handle a long slippery wire. Guidewire diameter is measured in an antiquated fashion; some equivalents are listed in Table 3 . However, the diameters 


\section{TABLE 2}

Characteristics of specific guidewires

Jagwire (Boston Scientific Endoscopy, USA)

- Slippery hydrophilic coating confined to part of the tip

- Stripes on the guidewire for positioning

- Sphincterotomy compatible

Pathfinder (Boston Scientific Endoscopy, USA)

- Slippery hydrophilic coating confined to part of the tip

Zebra (Boston Scientific Endoscopy, USA)

- Stripes on the guidewire for positioning

Tracer family (Wilson Cook Medical, USA)

- Slippery hydrophilic coating confined to part of the tip

- Sphincterotomy compatible

Protector family (Wilson Cook Medical, USA)

- Graduated markings on guidewire for positioning

- Sphincterotomy compatible

Director (Bard Endoscopic Technologies, USA)

- Slippery hydrophilic coating confined to part of the tip

Glidewire (Boston Scientific Endoscopy, USA)

- Slippery hydrophilic coating on the entire guidewire
- Sphincterotomy compatible

TABLE 3

Guidewire diameter equivalents

$0.035 \mathrm{in}=0.9 \mathrm{~mm}=2.7 \mathrm{Fr}$

$0.025 \mathrm{in}=0.635 \mathrm{~mm}=1.9 \mathrm{Fr}$

$0.018 \mathrm{in}=0.46 \mathrm{~mm}=1.4 \mathrm{Fr}$

It is important to shorten the intramural segment of the bile duct by lifting and angulating the papilla towards the 10 o'clock position for bile duct access (or towards the 3 o'clock position for pancreatic duct access) in order to facilitate entry of the wire into the desired duct. If this is unsuccessful, then one should try a 0.025-in or 0.018-in diameter guidewire. An angled tip is not advantageous in this situation because it might not orientate appropriately and there is usually insufficient space to rotate the wire.

Even after access papillotomy, many endoscopists use a guidewire before injecting contrast material in order to avoid an inadvertent submucosal injection. For the minor papilla, it is usually necessary to use a specially tapered catheter or sphincterotome positioned at the orifice together with a 0.021 -in or 0.018-in diameter guidewire. It is possible to cannulate either the major or minor papilla with a short length of guidewire protruding from the tip of the catheter or sphincterotome.

of accessory instruments, are usually denoted by their outer diameters (not their inner diameters), and so their lumen sizes must be remembered, colour coded or read from the label. The endoscopist must be sure that guidewires fit properly through accessories. Fortunately, the vast majority of accessories from all of manufacturers have inner diameters that can accommodate the standard 0.035-in guidewire.

\section{APPLICATIONS}

Communication between the endoscopist and the assistant are crucial. Imprecise instructions like 'in' and 'out' should be avoided unless they are understood by all personnel. The assistant should repeat instructions to confirm what they have heard, although it is possible to reduce the verbal interchange with experience. Inexperienced assistants might find it difficult to handle a long guidewire, but involvement of a second assistant is likely to complicate communication and manipulation. In general, all lumens through which guidewires are passed should be free of radiographic contrast material and flushed with water or saline.

\section{Access without ductography}

When attempts at cannulating the major papilla with a catheter or sphincterotome are unsuccessful, the options include the use of a guidewire or access papillotomy ('pre-cut') for all potentially therapeutic situations. In many cases, however, a cholangiogram (or less often, a pancreatogram) cannot be obtained and a decision for therapy cannot be made. The catheter or sphincterotome is then used to carry a straighttipped 0.035-in or smaller guidewire, preferably hydrophilic, which is manipulated by the assistant using short probing movements, while the endoscopist positions the catheter tip within the papilla. With some of the newer accessory assistance systems, it is possible for the endoscopist to perform these movements alone.

\section{Access after ductography}

After achieving pancreatography or cholangiography, deep cannulation of either duct is sometimes unsuccessful because of tortuosity of the instrasphincteric segments. In these cases, the techniques described above can be used, and fluoroscopic guidance is of additional help.

\section{Access papillotomy (entry cut, pre-cut)}

Access papillotomy should be considered when standard approaches to the bile duct or, less commonly, the pancreatic duct are unsuccessful and there is a clear indication (usually therapeutic) for cannulation. It should be undertaken by experienced endoscopists who achieve high success rates at conventional ERCP techniques and who perform many therapeutic procedures. The most important advantages of difficult situations without resorting to repeated instrumentation. This might reduce the risk of pancreatitis. My reading of the literature and anecdotal experience from around the world suggests that the overall use of access papillotomy is approximately $12 \%$ of ERCPs (range $4 \%$ to $23 \%$ ) with a primary success rate of approximately $80 \%$, a secondary success rate of approximately $90 \%$ and an associated complication rate of $13 \%$.

The use of access papillotomy is no excuse for poor endoscopic technique. The risks of this technique are well documented (1-4). High complication rates occur in some centres, especially with inexperienced endoscopists. Most published end of a sequence of other attempts, which results in a bias against the former.

A number of devices is available, ranging from a standard sphincterotome with an electrocautery wire exiting from the tip to various types of exposed straight electrocautery wires (known as the needle-knife). These devices require mere access papillotomy are improved access to the biliary duct in series, however, feature electrocautery access techniques at the 
contact with the tissue to create an effect since the current density is very great. Care must, therefore, be taken to place the wire accurately for initiating the cut, move the instrument in the correct direction, guide the depth of the incision and minimize unwanted tissue destruction at and deep to the site. I employ pulsed current, which provokes less tissue injury. The direction of incision must be modified in certain circumstances; for example, the bile duct extends in the 7 o'clock direction (inverted papilla) in cases of Billroth II gastrojejunostomy or Roux-en-Y anastomosis.

The segment of the bile duct that is 'incised' is the same intraduodenal or intramural segment that prevented success with standard approaches. It is never necessary to cut deeper into the duodenal wall than the plane of the muscle layer, because the biliary and pancreatic sphincters are always superficial to this. The intent is to create an opening directly into the bile duct or its sphincter. If the technique is unsuccessful, there should be no further attempts until $48 \mathrm{~h}$ have elapsed. Otherwise, iatrogenic swelling obscures the landmarks. If an obstructed duct has been entered, the usual considerations about biliary drainage apply.

I place the tip of the needle-knife at the papillary orifice and activate the electrocautery power while moving the device cephalad in the direction of the intramural bile duct. The direction of the cut is the most critical aspect of the procedure and determines its success or failure. Repeated passes of the knife are made in the same axis at progressively deeper levels until the wound is laid open and the 'internal' structures are revealed. It is important to constantly inspect the area for any drops of bile that would reveal the location of the bile duct, which can then be directly cannulated. This will not occur in patients with complete biliary obstruction, in whom anatomical landmarks must be sought. The biliary sphincter/intramural duct complex appears as a whitish mound if the incision is made to one side of the structure, or as circular muscle fibres if the cut has been made across it. Either the needle-knife catheter or a standard catheter or sphincterotome can be employed to cannulate the duct. Unless deep cannulation is easily achieved, it is advisable to first probe the site with a hydrophilic guidewire, in order to avoid inadvertently creating a false track.
I have also employed other techniques that will not be described in detail here. For example, a cut can be made down to a stent that has already been inserted into the bile duct. Occasionally, local pathology at the papilla or distal duct (eg, impacted stone, ampullary tumour, choledochocele or papillary stenosis) prevents cannulation. Impacted gallstones cause the bile duct to become grossly dilated and thin-walled. The needleknife can be employed to incise the duct proximal to the papilla, thereby effectively producing a fistulotomy. It is also possible to use the needle-knife and continuous cautery to open up a choledochocele. Patients with stenosis of a surgically created pancreaticojejunostomy are subject to recurrent pancreatitis, which can be treated by incision of the pancreatic duct using the needle-knife. In such cases, the duct can be readily identified because it forms a bulge when pancreatic secretion is augmented by infusion of secretin.

\section{CONCLUSIONS}

Guidewire technology has grown in complexity and sophistication with ERCP techniques. It is imperative that all members of the team are familiar with the characteristics and specifications of guidewires and accessories in their unit. Access papillotomy is difficult to master (5) and is associated with an increased risk of complications, but is often successful in difficult cases.

\section{REFERENCES}

1. Bruins Slot W, Schoeman MN, Disario JA, Wolters F, Tytgat GN, Huibregtse K. Needle-knife sphincterotomy as a precut procedure: A retrospective evaluation of efficacy and complications. Endoscopy 1996;28:334-9.

2. Vandervoort J, Carr-Locke DL. Needle-knife access papillotomy: An unfairly maligned technique? Endoscopy 1996;28:365-6.

3. Freeman ML, Nelson DB, Sherman S, et al. Complications of endoscopic biliary sphincterotomy. N Engl J Med 1996;335:909-18.

4. Vandervoort J, Soetikno RM, Tham TC, et al. Risk factors for complications after performance of ERCP. Gastrointest Endosc 2002;56:652-6.

5. Harewood GC, Baron TH. An assessment of the learning curve for precut biliary sphincterotomy. Am J Gastroenterol 2002;97:1708-12. 


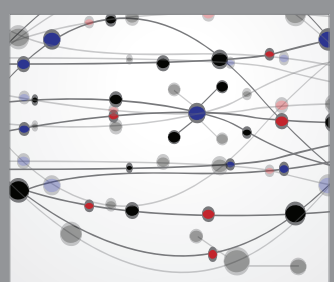

The Scientific World Journal
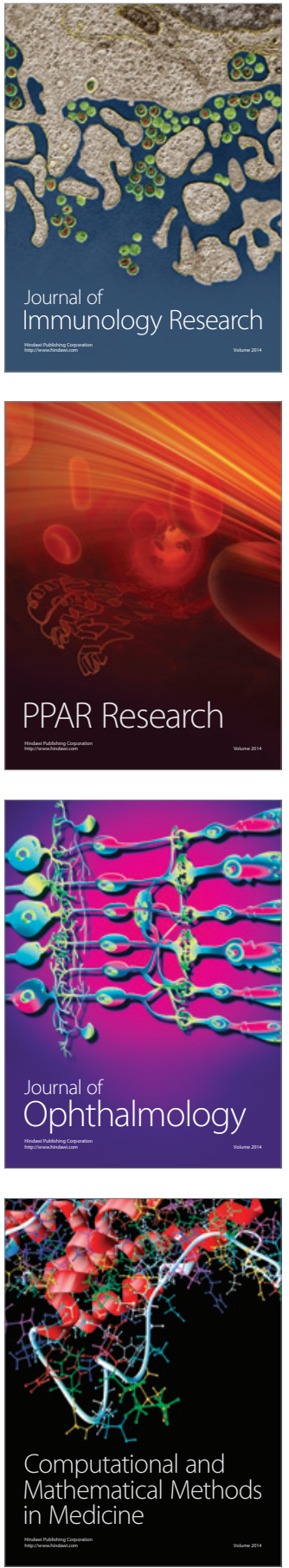

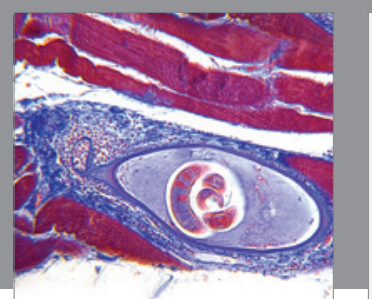

Gastroenterology Research and Practice

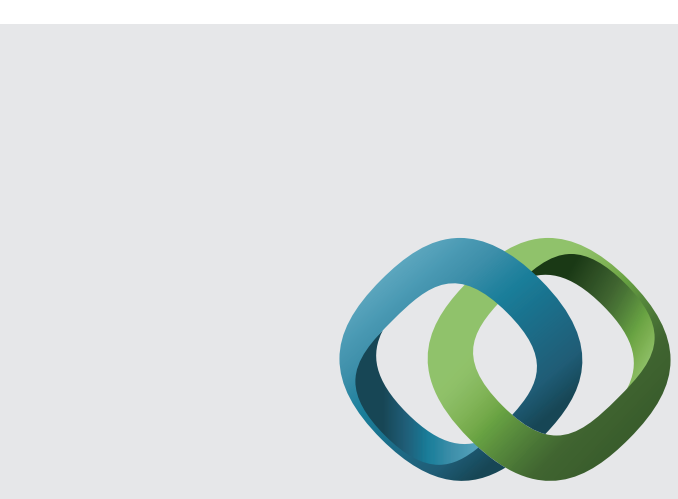

\section{Hindawi}

Submit your manuscripts at

http://www.hindawi.com
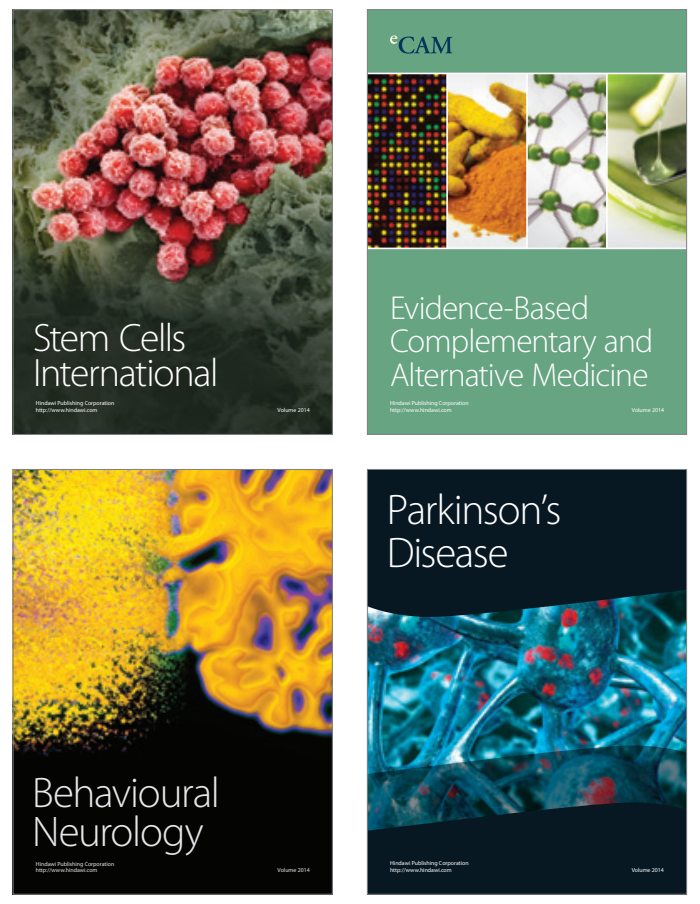
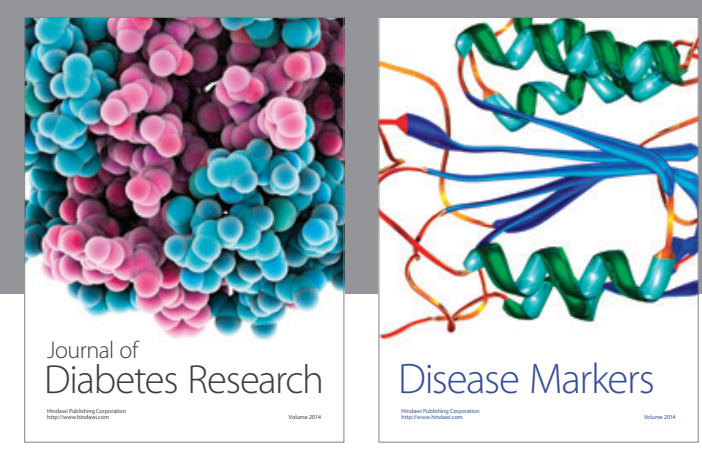

Disease Markers
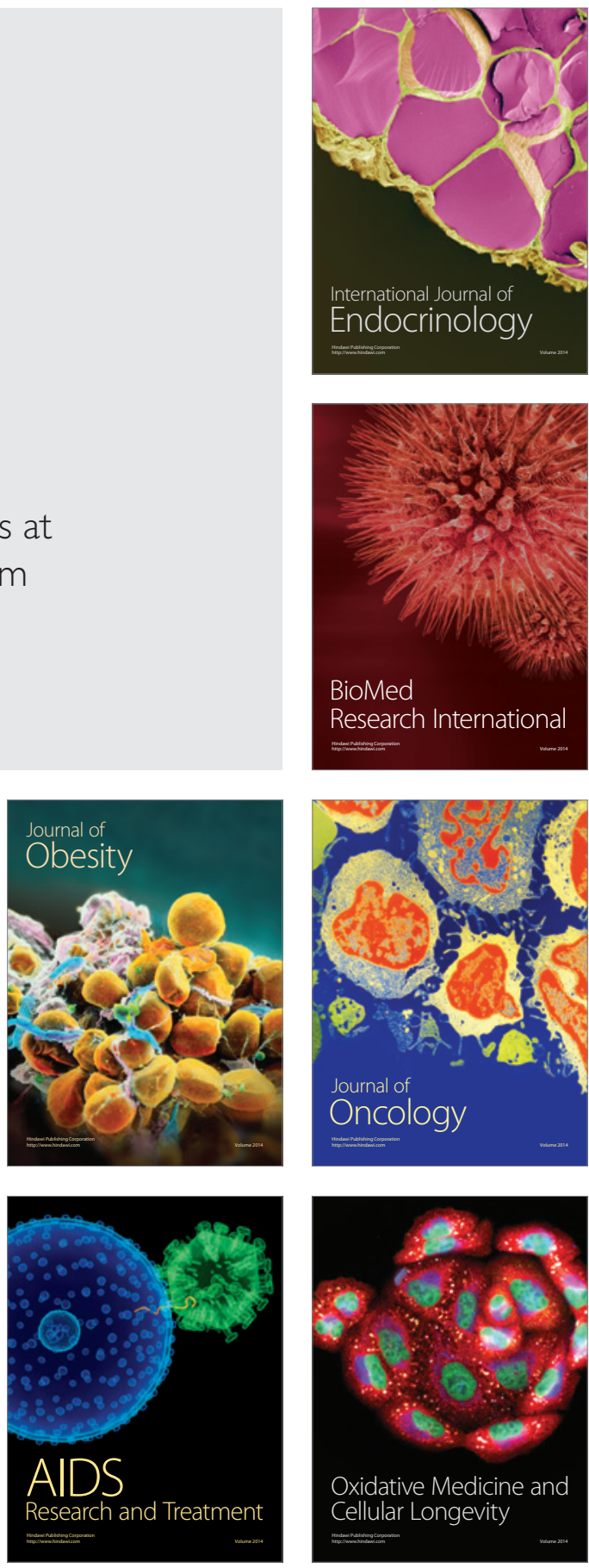